\title{
Iron load
}

\section{Filippo Cassarà, Aurelio Maggio \\ U.O.C. Ematologia II, A.O.C. Villa Sofia-V. Cervello, Palermo, Italy}

\begin{abstract}
Recent research addressed the main role of hepcidin in the regulation of iron metabolism. However, while this mechanism could be relevant in causing iron load in Thalassemia Intermedia and Sickle-Cell Anemia, its role in Thalassemia Major (TM) is marginal. This is mainly due to the high impact of transfusional requirement into the severe increase of body iron. Moreover, the damage of iron load may be worsened by infections, as HCV hepatitis, or liver and endocrinological damage. One of the most relevant associations was found between splenectomy and increase of risk for mortality due,probably, to more severe iron load. These issues suggest as morbidity and mortality of this group of patients they do not depend only by our ability in controlling heart damage but even in preventing or treating particular infections and complications. This finding is supported by the impairment of survival curves in patients with complications different from heart damage. However, because, during recent years different direct and indirect methods to detect iron overload in patients affected by secondary hemochromatosis have been implemented, our ability to maintain under control iron load is significantly improved. Anyway, the future in iron load management remains to be able to have an iron load map of our body for targeting chelation and other medical treatment according to the single organ damage.
\end{abstract}

\section{Introduction}

Iron metabolism is stringently regulated in our body. This is due because of its possible increase may determine severe organ damage. The total iron body content is from 3 to 4 grams (1). Haemoglobin approximately contains 2.5 grams of iron (1). Iron containing proteins is $400 \mathrm{mg}$ (1). Iron bound to transferrin in plasma is from 3 to $7 \mathrm{mg}$, while the remainder storage is contained as iron ferritin or hemo-

Correspondence: Aurelio Maggio

(C) Copyrigh F. Cassarà and A. Maggio, 2013

Licensee PAGEPress, Italy

Thalassemia Reports 2013; 3(s1):e5

doi:10.4081/thal.2013.s1.e5

This article is distributed under the terms of the Creative Commons Attribution Noncommercial License (by-nc 3.0) which permits any noncommercial use, distribution, and reproduction in any medium, provided the original author(s) and source are credited.

Parts of this work were presented at the

"3rd Pan-European Conference on Haemoglobinopathies and Rare Anaemias", Limassol (Cyprus), 24-26 October 2012. siderin proteins (1). Iron is lost in sweat, shed skin cells, and perhaps some gastrointestinal loss at a rate of approximately $1 \mathrm{mg} /$ day (1). Recent research has been addressed as hepicidin has a central role in iron homeostasis (2). The main role of hepcidin, secreted into the circulation, is to downregulate the ferroportin-mediated release of iron from enterocytes, macrophages and hepatocytes (Figure 1) (2). Actually, iron is reduced to the ferrous state by duodenal ferric reductase (DcYtb), it is transported into the cells by divalent metal transporter 1 (DMT1) and released by way of ferroportin (Figure 1) (1). Moreover, hepatocytes take up iron from circulation either as free iron or transferrin-bound iron (1). Furthermore, transferrin receptor 2 may serve as a sensor of circulating transferrin-bound iron (Figure 1) (1).

This mechanism of iron overloading could be relevant in patients with thalassemia intermedia and sickle-cell anemia, but it is not crucial in patients with thalassemia major. In this cohort of patients iron body burden is determined by transfusional requirement. As we know, transfusional regimen, to maintain pre-transfusion haemoglobin level around $10 \mathrm{~g} / \mathrm{dl}$, was shown to be able to promote normal growth, to give a good quality of life, to avoid or delay splenectomy, and to minimize iron overload (3). Calculation of annual blood requirement and transfusional iron loading by regular recording of transfused blood for each patient is necessary for monitoring the hypersplenism and to establish a tailored chelation treatment, possible today thanks to the availability of different iron chelators. However, one unit of transfused blood contains around 200-250 mg of iron (4). Moreover, iron accumulates with repeated infusions. Therefore, chronic transfusion-dependent patients have an iron excess of $\sim 0.4-0.5 \mathrm{mg} / \mathrm{kg} /$ day $(1 \mathrm{~g} / \mathrm{month})$ and first signs of iron overloading can be seen after 10-20 transfusions (4). Finally, the severe increase of iron in our body, causing severe organ damage, is followed from high impact on morbidity and mortality.

Therefore, hypogonadism (about 50\%), hypotiroidism (about 10\%) and hypoparathyroidism (about 9\%) remain some of the most common complications and hormone replacement therapy (HRT) is the only way to treat these. Moreover, insulin dependent diabetes affects several thalassemia patients, not considering that impairment of $\beta$-cell function (as determined by SC Homa) is detected earlier (5). Severe Growth Hormone Deficiency (GHD) was recently detected in 25\% of adult patients with major or intermedia thalassemia, being in these patients the mean femoral T-score significantly lower $(p<0.01)$. Posttransfusional viral infections affected patients transfused before introduction of screening tests on donor blood and are mainly related to HIV (less than 2\%) and HCV (up to 70\%) (6). Moreover, transfusional liver iron overloading together with HCV hepatitis increases the risk of fibrosis evolution (6). Therefore, although the most efficacious antiviral therapy for chronic HCV hepatitis is today based on the association of Peg-Interferon plus Ribavirin, with cumulative Sustained Virological Response (SVR) over 45\% (obtained in a small cohort of thalassemia patients), the extension of this antiviral combined treatment is actually delayed by the secondary hemolytic anemia due to ribavirin (6). Moreover, the patients with clinical and/or histological diagnosis of cirrhosis are about $8 \%$ (7) of risk for hepatocellular carcinoma (HCC) and, for this reason, they periodically have to receive appropriate screening (8). 
It is well known as cardiac disease-free survival is related to the frequency of serum ferritin levels less than $2500 \mathrm{ng} / \mathrm{ml}$. This means that patients with more than $67 \%$ of ferritin levels $>2500 \mathrm{ng} / \mathrm{ml}$ have poor prognosis, while patients with less than $33 \%$ of ferritin levels $>2500$ $\mathrm{ng} / \mathrm{ml}$ have nice prognosis. Intermediate prognosis was found in patients with thalassemia major with 33 to $67 \%$ of ferritin levels determinations $>2500 \mathrm{ng} / \mathrm{ml}$ (Figure 2) (9).

Recently, it was shown as even past-heart failure, cirroshis and arrythmia together with other complications, including endocrinological complications are related with higher risk for mortality on separate Cox regression model (Figure 3) (10). One of the most relevant associations was that between splenectomy and increase of risk for mortality (Figure 3) (10). This finding suggests as this organ could be crucial to decrease the risk for mortality because its high capacity of iron storage without any risk for tissue damage. This result could induce to revaluate needing for splenectomy, especially in countries where blood transfusion requirement, to maintain haemoglobin level $>9.5 \mathrm{~g} / \mathrm{dl}$ can be obtained. Moreover, Kaplan-Meier curves for single complication were obtained, suggesting as impairment of survival curves in thalassemia major does not depends only by cardiac disease (Figure 4).

These findings suggest as the main aim of treatment managing in thalassemia major patients should be to prevent organ damage as liver and endocrinological diseases together with high serum ferritin levels. Moreover, they suggest as the way to obtain this goal is not only to manage chelation treatment for maintaining, as long as possible, serum ferritin levels $<2500 \mathrm{ng} / \mathrm{ml}$ but even to make all other interventions necessary to prevent organ damage (i.e. HBV vaccination, regular blood transfusions, endocrinological survey, etc.).

During recent years, different direct and indirect methods to detect iron overload in patients affected by secondary hemochromatosis have been implemented (Figure 5).

Among these, serum ferritin levels determination is so far the most worldwide available tool. However, although this procedure is easy and available, it does not correlate with Liver Iron Concentration (LIC) in single cases (Figure 5).

In recent years, non-invasive methods to measure liver iron overload have been studied. Noninvasive methods for measuring liver iron overload, such as biosusceptometry by superconducting quantum interference device systems and magnetic resonance imaging (MRI), have been evaluated in thalassemia and hemochromatosis patients. After the initial report in 1982 (11), subsequent studies of superconducting quantum interference device biosusceptometry in clinical applications were limited to only a few specialized centres (12).. A strong correlation was demonstrated between liver iron concentration by biopsy and a quantitative measurement of the MRI signal amplitude using the R2 or R2* methodology (Figure5) (13-15). These evidences on accuracy of non-invasive methods for assessment of liver iron concentration are sufficient to consider MRI-R2 methodology as a worldwide available alternative to liver biopsy for liver iron measurement. However, liver biopsy is still considered the gold standard for the evaluation of liver damage and is recommended for the assessment of HBV or HCV chronic hepatitis by international guidelines (Figure5) (16).

To date the gradient echo $\mathrm{T} 2 *$ technique is the most robust method, allowing sensitive, rapid and reproducible quantification of myocardial iron (17-19) (Figure 5). The most recent multiecho (single breathhold) T2* versus the single echo (multi breath hold) $\mathrm{T} 2 *$ technique has permitted faster and more reproducible exams (18).

Thus, using a multislice multiecho $\mathrm{T}^{*}$ approach it has been possible to extend myocardial iron evaluation from the mid-ventricular septum to all left ventricle by a segmental approach (19-20). In fact, histological and MRI studies have previously demonstrated heterogeneous myocardial iron distribution. The multislice multiecho $\mathrm{T} 2 *$ approach accounting for the heterogeneous myocardial iron distribution has permitted to identify three groups of patients (homogeneous, heteroge- neous, and no myocardial iron overload) that are statistically different in serum ferritin levels and liver iron concentration (19).

Recently, Kirk P, et al. (21) suggested as T2* values $<10 \mathrm{~ms}$ (Relative Risk 159, $\mathrm{P}<0.001)$ and $\mathrm{T} 2 *<6(\mathrm{RR} 268, \mathrm{P}<0.001)$ were associated with a significantly increased risk of heart failure in comparison with cardiac $\mathrm{T} 2 *$ values $>20 \mathrm{~ms}$ (Figure 6 ).

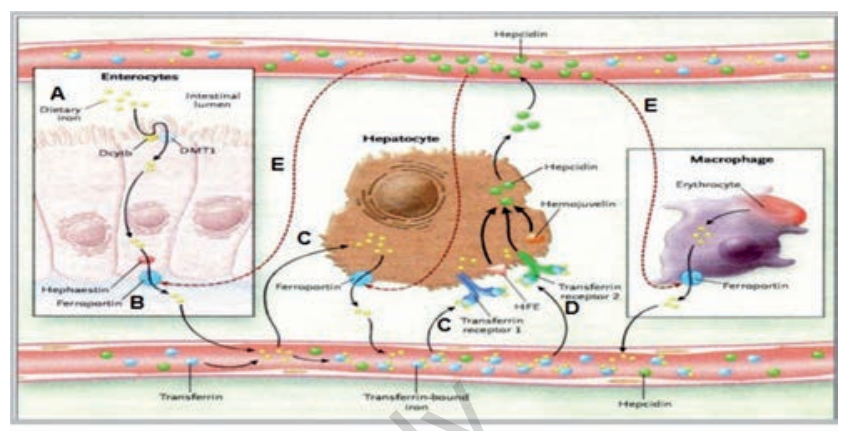

A:Iron is reduced to the ferrous state by duodenal ferric reductase (Dcytb).B:Iron is transported into the cell by divalent metal transporter 1 (DMT1) and released by way of ferroportin C: Hepatocytes take up iron from the circulation either as free iron or transferrin-
bound iron D: Transferrin receptor 2 may serve as a sensor of circulating transferrin-bound iron $\mathbf{E}$ : Hepicidin is secreted into the circulation, where it downregulates the ferroportinmediated release of iron from enterocytes, macrophages and hepatocytes.

Figure 1. Hepcidin control of iron homeostasis: minor role in thalassemia major.

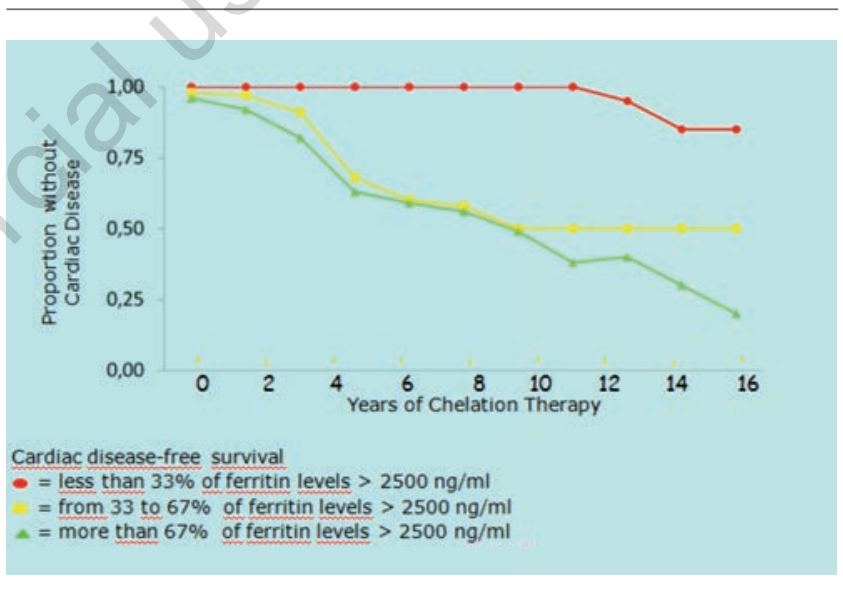

Figure 2. Cardiac disease-free survival corresponding to different percentages of serum ferritin levels exceeding $2500 \mathrm{ng} / \mathrm{ml}$ (Olivieri et al.,1994).

\begin{tabular}{lccc} 
COMPLICATION & HR $(95 \% \mathrm{Cl})$ & p-value & $\begin{array}{c}\text { N. SUBJECTS } \\
\text { (DEATHS) }\end{array}$ \\
\hline PAST-HEART FAILURE & $10,7(5,8 ; 19,7)$ & $<0,0001$ & $357(41)$ \\
CIRROSHIS & $8,1(3,9 ; 16,6)$ & $<0,0001$ & $341(31)$ \\
ARRYTHMIA & $6,8(3,8 ; 12,1)$ & $<0,0001$ & $367(47)$ \\
DIABETES & $5,3(3,1 ; 9)$ & $<0,0001$ & $383(59)$ \\
HYPOPARATHYROIDISM & $5,1(2,3 ; 11,4)$ & $<0,0001$ & $332(28)$ \\
CARDIOPATHY & $3,9(2,1 ; 7,4)$ & $<0,0001$ & $174(41)$ \\
HYPOTHYROIDISM & $3,4(1,6 ; 7,3)$ & 0,001 & $346(28)$ \\
HYPOGONADISM & $2,9(1,3 ; 6,5)$ & 0,01 & $348(31)$ \\
SPLENECTOMY & $2,8(1,6 ; 4,9)$ & $<0,0001$ & $379(53)$ \\
MEANFERRITIN $(<2500$ VS $\geq 2500)$ & $4,2(2,6 ; 6,5)$ & $<0,0001$ & $417(77)$ \\
\hline
\end{tabular}

Figure 3. Summary of overall survival based on separate cox regression models for single complication (Maggio et al., 2012, unpublished data). 
Moreover, cardiac echo-doppler has a prominent value either in evaluating the severity of right and left heart dysfunction and in identifying prognostic factors of heart failure. Recently, our group suggested as reduction in LVEF $\geq 7 \%$, over time, determined by 2-D echocardiography, may be considered a strong predictive tool for the detection of thalassemia major patients with increased risk of cardiac death (Figure 7, Table 1) (submitted paper). The reduction of $\mathrm{LVEF} \% \geq 7 \%$ had higher (84.76\%) predictive value. Finally, Kaplan-Meier survival curves of thalassemia major patients with LVEF $\geq 7 \%$ showed a statistically significant decreased probability of survival for heart disease ( $p=0.0022)$ (Figure 8).
Finally, different approaches have been performed to detect iron overloading in different organs as pituitary gland, brain, pancreas, adrenals, spleen, lymph node and bone marrow. Moreover, the possibility of detecting single organ iron body burden is the main challenge for the future and it could change the clinical approach to chelation treatment in thalassemia major patients, targeting specific chelation for single organ damage. However, none of the study, reported on literature and concerning the iron overloading evaluation of these organs, suggests, so far, that MRI of organs different from liver and heart could be performed with sufficient reliability and reproducibility on routinely standard clinical practice.

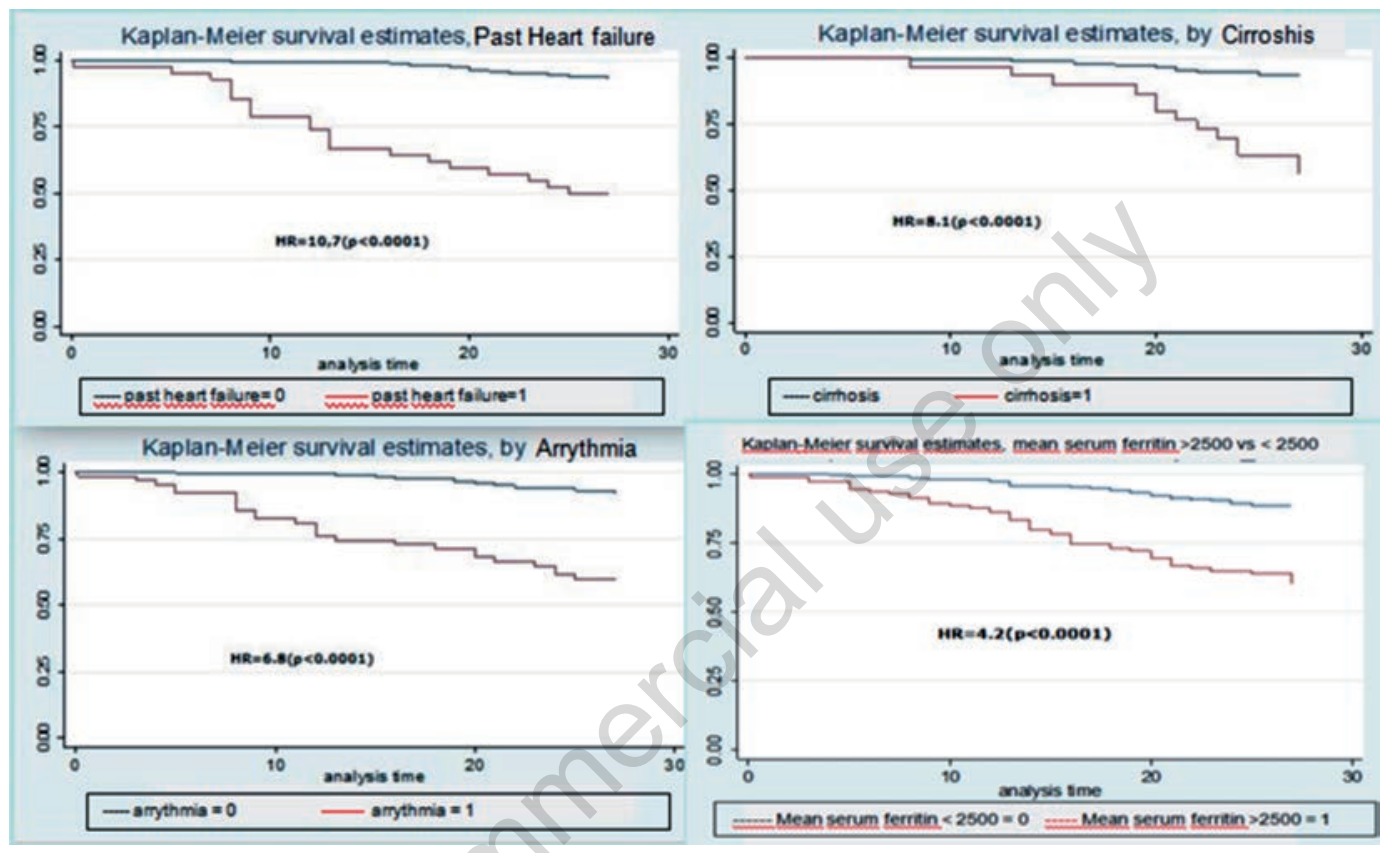

Figure 4. Kaplan-Meier survival curves in thalassemia major patients for single complication (Maggio et al., 2012, unpublished data).

\begin{tabular}{|c|c|c|}
\hline \multirow{3}{*}{ INDIRECT } & METHODS & EVALUATION \\
\hline & FERRITIN & $\begin{array}{l}\text { Easily, available } \\
\text { Useful as an index of compliance with } \\
\text { therapy } \\
\text { Does not correlate with LIC in single cases }\end{array}$ \\
\hline & $\begin{array}{l}\text { TRANSFERRIN } \\
\text { SATURATION }\end{array}$ & $\begin{array}{l}\text { Useful in genetic hemochromatosis and } \\
\text { thalassemia intermedia } \\
\text { Not useful in thalassemia major }\end{array}$ \\
\hline \multirow{3}{*}{ DIRECT } & $\begin{array}{l}\text { LIVER } \\
\text { BIOPSY }\end{array}$ & $\begin{array}{l}\text { "Gold standard" for the evaluation of liver } \\
\text { damage (International Guidelines) } \\
\text { It is invasive, accuracy for LIC } \\
\text { determination in presence of fibrosis and } \\
\text { cirrhosis could be lower }\end{array}$ \\
\hline & NMR (MRI):R2* and T2* & $\begin{array}{l}\text { R2* is the "gold standard" procedure for } \\
\text { LIC } \\
\text { T2* is the only available tool to evaluate } \\
\text { heart iron }\end{array}$ \\
\hline & SQUID & $\begin{array}{l}\text { Reproducibility in very specialized centers } \\
\text { - Available only in few centers }\end{array}$ \\
\hline
\end{tabular}

Figure 5. Direct and indirect methods to detect iron overload in patients affected by secondary hemochromatosis. 


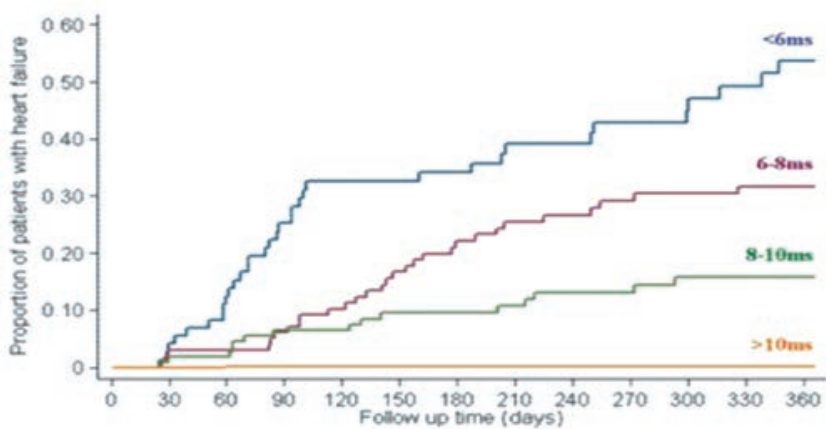

Figure 6. Lower heart $\mathrm{T}^{*}$ values are associated with increased risk for heart failure (Kirk et al., 2009).

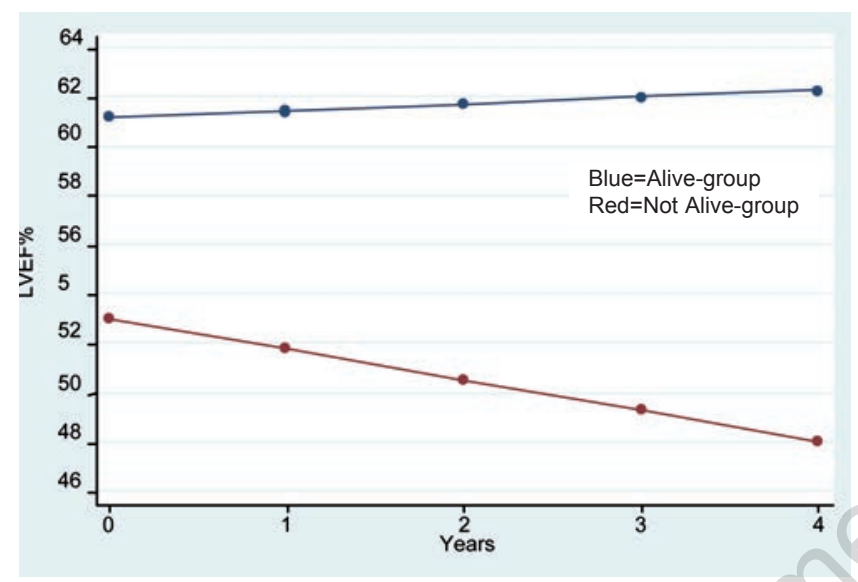

Figure 7. Estimated profiles from the fitted GEE model for the two patient-groups: the not alive (red color) versus the alivegroup (black color) (Maggio et al. 2012, submitted).

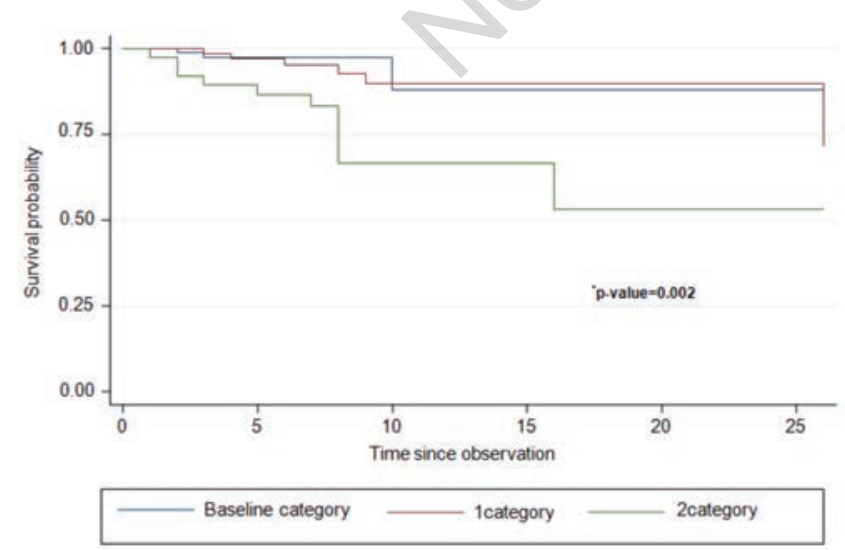

p-value from log-rank test

Figure 8. Kaplan-Meier curves for cardiac disease mortality in the three categorized Thalassemia Major groups. The 2 category was represented from patients with a LVEF $>7 \%$ during the time.
Table 1. GEE model to evaluate changes in mean ejection fraction levels in not alive-group versus alive-group over time.

\begin{tabular}{lccc}
\hline & $\begin{array}{c}\text { Coefficients } \\
\text { (SE') }\end{array}$ & $95 \% \mathrm{Cl}^{*}$ & p-value \\
\hline Intercept & $60,89(0,61)$ & $(59,69 ; 62,09)$ & $<0,0001$ \\
Status $^{*}$ & $-6,58(1,78)$ & $(-10,08 ;-3,07)$ & $<0,0001$ \\
Year $^{*}$ & $0,27(0,13)$ & $(-0,001 ; 0,54)$ & 0,051 \\
Status×Year $^{*}$ & $-1,51(0,41)$ & $(-2,31 ;-0,71)$ & $<0,0001$ \\
\hline
\end{tabular}

$\mathrm{SE}^{*}=$ Standard Error, $\mathrm{Cr}^{*}=$ Confidence Interval, P-value ${ }^{*}$ from null hypothesis coefficient $=0$ by Wald's test. Status" is the variable indicating if a patient is dead or alive; Year" is the variable indicating the consecutive years of observation, corresponding to $t=0,1,2,3,4$; Status $\times$ Year" $"$ is a status-by-time interaction effect.

\section{Conclusions}

In conclusion, although iron homeostasis is mainly controlled by hepcidin secretion, its role in the iron loading of thalassemia major patients is not relevant and transfusion remain the main cause of organ damage in this cohort of patients.

Therefore,the control of this has a central role in the management of thalassemia major patients. The aim of our treatment should be addresed to prevent all possible organs damage, considering that some of them have highest impact on the impairment of survival curves of these patients.

Moreover, the general clinical management of all other possible factors that may impair organ functionality should accompany the control of iron body burden. This approach is today possible thanks to the improvement of sensibility and specificity of non-invasive methods to measure liver and heart iron overloading.

The future in iron load management remains to be able to have an iron load map of our body for targeting chelation and other medical treatment according to the single organ damage.

\section{References}

1. Muñoz M, Villar I, García-Erce JA An update on iron physiology. World J Gastroenterol. 2009 Oct 7;15(37):4617-26.

2. Nemeth E, Tuttle MS, Powelson J, Vaughn MB, Donovan A, Ward DM, Ganz T, Kaplan J. Hepcidin regulates cellular iron efflux by binding to ferroportin and inducing its internalization. Science 2004; 306: 2090-2093.

3. Guidelines for the Clinical Management of Thalassaemia 2ND Edition. Thalassaemia International Federation, December 2007.

4. Porter JB. Practical management of iron overload. Br J Haematol 2001;115:239-252.

5. Angelopoulos NG, Zervas A, Livadas S, Adamopoulos I, Giannopoulos D, Goula A, Tolis G. Reduced insulin secretion in normoglycaemic patients with beta-thalassemia major. Diabet Med 2006; 23(12):1327-31.

6. Di Marco V, Capra M, Angelucci E, Borgna-Pignatti C, Telfer P, Harmatz P, Kattamis A, Prossamariti L, Filosa A, Rund D, Gamberini MR, Cianciulli P, De Montalembert M, Gagliardotto F, Foster G, Grangè JD, Cassarà F, Iacono A, Cappellini MD, Brittenham GM, Prati D, Pietrangelo A, Craxì A, Maggio A; Italian Society for the Study of Thalassemia and Haemoglobinopathies; Italian Association for the Study of the Liver. Management of chronic viral hepatitis in patients with thalassemia: recommendations from an international panel. Blood 2010 0ct 21;116(16):287583. Epub 2010 Jun 15. 
7. Borgna-Pignatti C, Rugolotto S, De Stefano P, Zhao H, Cappellini MD, Del Vecchio GC, Romeo MA, Forni GL, Gamberini MR, Ghilardi R, Piga A, Cnaan A. Survival and complications in patients with thalassemia major treated with transfusion and deferoxamine. Haematologica 2004; 89:1187-1193.

8. Mancuso A, Sciarrino E, Renda MC, Maggio A. A prospective study of hepatocellular carcinoma incidence in thalassemia. Hemoglobin 2006; 30(1):119-24.

9. Olivieri NF, Nathan DG, MacMillan JH, Wayne AS, Liu PP, McGee A, Martin M, Koren G, Cohen AR. Survival in medically treated patients with homozygous beta-thalassemia. N Engl J Med. 1994 Sep 1;331(9):574-8.

10. Maggio A, Vitrano A, Capra M, Cuccia L, Gagliardotto F, Filosa A, Magnano C, Rizzo M, Caruso V, Gerardi C, Argento C, Campisi S, Cantella F, Commendatore F, D’Ascola DG, Fidone C, Ciancio A, Galati MC, Giuffrida G, Cingari R, Giugno G, Lombardo T, Prossomariti L, Malizia R, Meo A, Roccamo G, Romeo MA, Violi P, Cianciulli P, Rigano P.Improving survival with deferiprone treatment in patients with thalassemia major: a prospective multicenter randomised clinical trial under the auspices of the Italian Society for Thalassemia and Hemoglobinopathies. Blood Cells Mol Dis. 2009 May-Jun;42(3):247-51. Epub 2009 Feb 23.

11. Brittenham GM, Farrell DE, Harris JW, et al. Magnetic-susceptibility measurement of human iron stores. $N$ Engl J Med 1982;307(27):1671-167

12. Fischer R, Farrell D. Liver iron susceptometry. In: Andrew M, Nowak H, editors. Magnetism in Medicine: A Handbook [completely revised and extended edition]. Berlin, Germany: Wiley-VCH; 2007;529-549.

13. St Pierre TG, Clark PC, Chua-Anusorn W, et al. Noninvasive measurement and imaging of liver iron concentrations using proton magnetic resonance. Blood 2005;105(2):855-861.

14. Wood JC, Enriquez C, Ghugre N, et al. MRI R2 and R2* mapping accurately estimates hepatic iron concentration in transfusion- dependent thalassemia and sickle cell disease patients. Blood 2005;106(4):1460-1465.

15. Hankins JS, McCarville MB, Loeffler RB, et al. R2* magnetic resonance imaging of the liver in patients with iron overload. Blood 2009;113(20):4853-4855.

16. McCaughan GW, Omata M, Amarapurkar D, et al. Asian Pacific Association for the Study of the Liver consensus statements on the diagnosis, management and treatment of hepatitis $\mathrm{C}$ virus infection. J Gastroenterol Hepatol 2007;22(5):615-633.

17. Anderson LJ, Holden S, Davis B, Prescott E, Charrier CC, Bunce NH, Firmin DN, Wonke B, Porter J, Walker JM, Pennell DJ. Cardiovascular T2-star (T2*) magnetic resonance for the early diagnosis of myocardial iron overload. Eur Heart J 2001; 22:21712179.

18. Westwood M, Anderson LJ, Firmin DN, Gatehouse PD, Charrier CC, Wonke B, Pennel DJ. A single breath-hold multiecho T2* cardiovascular magnetic resonance technique for diagnosis of myocardial overload. J Magn Reson Imaging 2003; 18:33-39.

19. Positano V, Pepe A, Santarelli MF, Scattini B, De Marchi D, Ramazzotti A, Forni G, Borgna-Pignatti C, Lai ME, Midiri M, Maggio A, Lombardi M, Landini L Standardized T2* map of normal human heart in vivo to correct T2* segmental artefacts. NMR in Biomedicine. 2007; 20:578-590.

20. Pepe A, Positano V, Santarelli MF, Sorrentino F, Cracolici E, De Marchi D, Maggio A, Midiri M, Landini L, Lombardi M. Multislice multiecho $\mathrm{T} 2 *$ cardiovascular magnetic resonance for detection of the heterogeneous distribution of myocardial iron overload. J Magn Reson Imaging 2006; 23:662-668.

21. Kirk P, Roughton M, Porter JB, Walker JM, Tanner MA, Patel J, Wu D, Taylor J, Westwood MA, Anderson LJ, Pennell DJ Cardiac T2* magnetic resonance for prediction of cardiac complications in thalassemia major.Circulation. 2009 Nov 17;120(20):1961-8. Epub 2009 0ct 2.

\section{Oral presentation}

Oral presentation is available online 